Fecha de recepción: marzo 2020 Fecha de aceptación: abril 2020 Versión final: mayo 2020

\section{Discursos de la resistencia. La enunciación a través de la producción textil artesanal de mujeres migrantes}

Ximena Eliçabe ${ }^{(1)}$

\begin{abstract}
Resumen: Este escrito es un estudio de la producción de sentido generada a partir del trabajo textil de diferentes artesanas que participaron del proyecto Pertenencias, narraciones textiles de mujeres migrantes en el Hemisferio Sur.

Considerando los sistemas de representación en la producción de imágenes como relaciones que se establecen entre el discurso, el sujeto y los procesos histórico-sociales, apunta a encontrar en la dimensión discursiva de la obra, tanto como en el discurso verbal de sus autoras, aquellos elementos que construyen dos relatos en apariencia opuestos. La imagen ingenua del collage textil y del bordado, en contraposición a la dura realidad que les ha tocado vivir a quienes lo realizaron, narrada por ellas en entrevistas on y off the record.
\end{abstract}

Palabras clave: migración- arte textil - discurso - materialidad - enunciación.

[Resúmenes en inglés y portugués en la página 154]

(1) Ximena González Eliçabe es Diseñadora Textil (UBA). Artista e investigadora de las tradiciones textiles americanas. Es Profesora de la Universidad de Palermo en la Facultad de Diseño y Comunicación. Es consultora y capacitadora en temas de diseño y artesanía, trabajando en programas de instituciones públicas como el Ministerio de Turismo de la Nación, el Consejo Federal de Inversiones y otras. Realizó exposiciones y obtuvo diversos premios y menciones. Fue directora académica del Centro de Estudios Latinoamericanos La Abadía, Bs. As. Curó la muestra "Ponchos en el Bicentenario", en el Museo de Arte Popular José Hernández (MAP - 2017), Bs. As. Curadora y coordinadora del Proyecto "Pertenencias Narraciones textiles de mujeres migrantes en el Hemisferio Sur" en el MAP, ganador del Premio "Maleta Abierta" del Programa Iber-Rutas de la Secretaría General Iberoamericana (SEGIB). Es Directora de contenidos de ArgentinaXplora.com. En su actividad en la Universidad de Palermo publicó: "Arte, Diseño y artesanía. La metáfora textil como signo de identidad" (2005), "Experimentación, innovación, ciencia y diseño" (2006), "Diseño, educación y preservación del patrimonio cultural" (2006), "Introspección, el cuerpo" (2009). "Arte Textil y Tradición en la Prov. de Catamarca, Noroeste argentino" (2012). "Arte sartorial, de lo ritual a lo cotidiano" (2013), "El Tiempo y la materia, atributos del nuevo lujo" (2016). 


\section{Introducción}

Para comprender los fenómenos contemporáneos como los desplazamientos de grupos de personas, la integración y la diversidad cultural en distintos contextos, es necesario atender no sólo a las cuestiones que los originan, tales como la inestabilidad política, económi$\mathrm{ca}$, los desastres naturales, la opresión por temas étnicos o religiosos, sino también indagar en las experiencias individuales de quienes migraron. Los desplazamientos espaciales y culturales entre países o distintas regiones de un mismo país (de la periferia al centro) se reflejan en los procesos de estructuración de sentido de las producciones individuales o colectivas, de manera no siempre lineal o transparente.

El teórico y crítico de arte paraguayo Ticio Escobar nos dice que "el concepto de representación es engorroso porque promete presentar una idea o un objeto irremediablemente ausentes" (Escobar, 2009).

En apariencia, las producciones del arte popular suelen a menudo representar situaciones de la vida cotidiana, de la tradición. Sin embargo, detrás de un velo costumbrista o ingenuo podemos rastrear la presencia de otros significados. Esta veladura o ausencia de literalidad denota una forma de resistencia.

Escobar agrega, "la representación funciona como tarea de transparencia simbólica a cargo de las formas" (Escobar, 2009).

El discurso estético atraviesa los otros discursos, con un sentido propio. Determina cómo las representaciones, o bien las estrategias simbólicas, se convierten en un discurso de resistencia. La resistencia emerge, en este caso, como estrategia de supervivencia.

Pertenencias es un proyecto que integra experiencias textiles generadas en dos países, Nueva Zelanda y Argentina. Vincula problemáticas comunes de mujeres que se desplazan de su lugar de origen -parajes rurales- a los centros urbanos, donde olvidan o callan su herencia cultural. El textil relata esas vivencias.

El proyecto se lleva adelante en el Museo de Arte Popular José Hernández (MAP), Buenos Aires y cuenta con el auspicio de la Secretaría de Cooperación Iberoamericana, a través de la convocatoria "Maleta Abierta" de Iber-rutas.

Comprende varios ejes, las investigaciones consignadas en esta publicación, talleres de capacitación para artesanas migrantes, un coloquio y una exposición.

El concepto de Pertenencias se fue moldeando con distintos elementos, fue tomando forma a medida que se presentaban sus protagonistas y las piezas se iban hilvanando entre si, encontrando similitudes, patrones, eslabones en la cadena. En realidad se comenzó a advertir una estructura rizomatica, donde las voces de las migrantes resonaban en lo que denominé narraciones textiles.

Un artículo de la BBC publicado el 1 julio del 2018 acerca de unos dibujos hallados en el Vaticano en un manuscrito del siglo XIII llamó mi atención; mencionaba que los mismos echaban luz sobre nuestro conocimiento de las rutas comerciales medievales y modificaban la historia del comercio mundial. Eran dibujos de pájaros realizados entre $1241 \mathrm{y}$ 1248, que un grupo de investigadores australianos y finlandeses identificaron como las ilustraciones europeas mas antiguas de un tipo de pájaro originario de Australasia, la cacatúa de cresta amarilla o tritón. El libro que le perteneció al emperador romano Federico II estaba dedicado a la cetrería y evidenciaba que el hecho de que ese pájaro llegara a Sicilia 
en el siglo XVIII se debía a un gran flujo comercial que provenía del Medio Oriente y mas allá, según afirmó la Dra. Dalton, una de las investigadoras. Además, el descubrimiento cuestiona la visión eurocéntrica que afirma que Oceanía es una de las últimas regiones del mundo en ser descubiertas. La académica añadió que para esa época, pequeñas embarcaciones recorrían las islas comprando telas, pieles y animales vivos que comercializaban con otros mercaderes chinos, árabes y persas, en puertos de lugares como Java.

Este fenómeno de tránsito en la latitud Sur es antiguo, y fue forjado por la cultura. Otras causas impulsan esos desplazamientos en las últimas décadas, y tal vez los registros de los mismos sean menos idílicos y mas épicos. Por estas razones la figura poética del pájaro se propone como alegoría en el recorrido temático de la muestra Pertenencias...

La importancia de abordar integralmente el proyecto exigía un proceso de búsqueda del material humano considerablemente complejo en una gran ciudad como Buenos Aires, donde pocas de las personas con las características que requería el proyecto están agrupadas en colectivos. Por otro lado el espacio del museo debía ser el núcleo geográfico del mismo, ya que era una parte importante en el componente actitudinal del grupo que pudieran salir de su ámbito (su barrio, su grupo de referencia) abordando un nuevo desafío con independencia, y fundamentalmente porque el museo proveía el contacto con el patrimonio material que da testimonio de su cultura y sus saberes.

Los encuentros grupales previos a la muestra tendieron a generar un nuevo vínculo con su cultura y con sus pares, a asumirse como artesanas y desempeñar distintos roles, propiciando, como lo define Pablo Edmundo Heredia refiriéndose a la literatura del exilio latinoamericano, "un espacio interdiscursivo en donde se entrecruzan, por un lado, las voces y los registros de una geocultura regional -la memoria, oral y escrita; las prácticas y pertenencias sociales: las formas y mecanismos existenciales y vitales-" (Heredia, 1996).

La exposición, curada por quien escribe, estuvo compuesta por obras de tejedoras premiadas y anónimas muchas de ellas patrimonio del MAP y del Fondo Nacional de las Artes. También se exhibieron los trabajos en proceso del grupo de mujeres migrantes en Argentina y el resultado de los talleres "Travelling Sewing Box Project", con refugiadas y migrantes latinoamericanas en Nueva Zelanda, a cargo de la diseñadora argentina residente en ese país, Victoria Martínez Azaro, en colaboración con ALAC (Aotearoa Latin American Community Inc).

Pertenencias pretende tender un puente entre distintas latitudes que albergan a las portadoras de estos saberes, para construir lazos más fuertes de integración, para reconocerse y aceptarse en la diversidad.

La exposición se llevó a cabo del 12 junio al 19 de agosto de 2019 en el MAP, Av. del Libertador 2373, Buenos Aires. El coloquio se realizó después de la apertura de la misma, con el apoyo de la Universidad de Palermo.

En el presente trabajo se analizarán obras textiles contemporáneas que componen la exposición, dos de ellas pertenecen a colectivos de migrantes, unas, refugiadas colombianas en Hamilton, Nueva Zelanda; otras, artesanas argentinas y paraguayas que migraron del ámbito rural a la ciudad de Buenos Aires y sus alrededores. El tercer trabajo que se analizará es el de una artesana catamarqueña, que vive y trabaja en su pueblo, Belén, hilando, tejiendo y bordando vicuña, y que reflexiona sobre los que se fueron del "pago". 
El análisis de las piezas textiles pretende ahondar en dos dimensiones, una de aparente ingenuidad brindada por las imágenes y otra fundada en el relato oral de fuertes experiencias vividas, como la violencia, la discriminación, el desarraigo, la nostalgia.

También se tendrá en cuenta la cuestión de la materialidad, como uno de los primeros aspectos de significación que percibimos.

\section{Corpus}

El corpus está formado por tres casos, una obra colectiva en técnica de collage cosido, bordado y con apliques con material de descarte (retazos) de la industria de la moda, realizada por un grupo de refugiadas colombianas en Nueva Zelanda en el taller "Travelling Sewing Box Project".

Del mismo se hará foco en algunos detalles, dado que si bien se trata de un trabajo grupal, e indivisible de acuerdo al criterio de quienes lo generaron, tomaremos como muestra algunas individualidades para que pueda adecuarse al estudio del sujeto que realiza el acto de la enunciación.

Para el análisis se cuenta con el registro en audio de una de las artesanas, Fanny Zabala, que corresponde a su intervención en el coloquio realizado en el contexto de la exposición. Así mismo si bien no hay documentación de otros relatos de esta persona, pude tomar contacto personal con ella quien me contara algunos de los detalles de su historia personal como indígena y perseguida en Colombia, como refugiada.

El otro caso es el del grupo de artesanas migrantes del Taller Pertenencias en el MAP, algunas de ellas provenientes de la Provincia de Catamarca, otras de la provincia de Entre Ríos y del Paraguay. En este taller que dirijo en el MAP, planteamos un trabajo previo a la exposición con el grupo de artesanas que fueron seleccionadas por su condición de migrantes del ámbito rural al urbano, y por ser poseedoras de conocimientos vinculados a las técnicas textiles tradicionales. La consigna era realizar una obra grupal que iba a ser exhibida en la muestra, donde cada una aportara sus técnicas, sus materiales, su manera de ver su realidad como migrante y como artesana. Se sugirió la idea del pájaro, en cualquiera de sus aspectos, sin tomar en cuenta la literalidad. A medida que el grupo se fue consolidando se indagó en las historias que cada una traía con sigo, en cómo habían llegado a su lugar actual y qué cosas las vinculaban con el que dejaron atrás. El hilo conductor fueron precisamente los hilados, los tejidos, los telares, las madres y abuelas que les enseñaron el oficio. Trabajamos con frases y palabras que a cada una le surgían y entre todas armábamos textos (enunciados) que serían bordados en la pieza.

Aclaro que no tuve intervención alguna en la obra que ellas generaron, sino que mi rol fue como guía o facilitadora, dinamizando los conceptos, pero la ejecución y las decisiones finales fueron tomadas por ellas mismas en conjunto.

Los testimonios de las artesanas están registrados en un video que se exhibió en la sala ${ }^{1}$; también se realizaron entrevistas individuales cortas por separado con la investigadora Mirta Bialogorski y equipo del MAP. 
Por último, se analizará la obra de Juana Moreno de Herrero, de la Asociación de hilanderas de vicuña de Belén, Catamarca. Juana realizó la pieza especialmente para la exposición, desde el hilado manual con huso, el tejido y el bordado. Transformó el material más valioso, la fibra de vicuña, en una media manta o rebozo bordado con la figura de una mano que al abrirse deja salir pájaros que se van volando.

Se completa la narración con un mensaje de audio enviado por ella el día de la inauguración, donde da cuenta del significado que quiso darle a su obra.

\section{Desarrollo del análisis comparativo}

El objetivo de este análisis es buscar las huellas del sujeto en el discurso, tanto en el lenguaje visual de estas obras como en el lenguaje verbal de sus enunciantes.

Según Emile Benveniste, el discurso crea identidades, construye el YO y el TÚ, es una puesta en escena que busca provocar efectos en los enunciatarios. Y define a la enunciación como "el acto individual e histórico de apropiación activa de la lengua para producir un discurso" (Benveniste, 1966).

La enunciación es un proceso por el cual el acto de decir -enunciación-, produce un enunciado, producto de la apropiación, donde existen las huellas del sujeto. Al enunciado se lo distingue como lo realizado, el producto. En cambio la enunciación, se entiende como 'la puesta en funcionamiento de la lengua', un 'acontecimiento' en la línea del tiempo que se concibe -por su propia naturaleza-irrepetible, incognoscible.

Considerando la eficacia del arte en tanto lenguaje -visual, sonoro, verbal, corporal- capaz de consolidarse en los acontecimientos históricos, y las relaciones que se establecen entre el discurso, el sujeto y estos procesos histórico-sociales, inferimos que no sólo pone de manifiesto una realidad o problemática determinada, sino que construye una forma de entendimiento, de transmisión, que impacta en la sociedad generando una clave de lectura de nuestros tiempos.

Al respecto Ticio Escobar señala:

El arte ya no interesa tanto como lenguaje sino como un discurso cuya performatividad lo descentra de sí y lo empuja hacia fuera. Por eso, cada vez más se evalúa la obra no ya verificando el cumplimiento de los requisitos estéticos de orden o armonía, tensión formal, estilo y síntesis, sino considerando sus condiciones de enunciación y sus alcances pragmáticos: su impacto social, su inscripción histórica, su densidad narrativa o sus dimensiones éticas (Escobar, 2009).

\section{Caso \#1: La tela de Hamilton}

En el caso de la obra colectiva del grupo de refugiadas colombianas, encontramos historias enlazadas por la sucesión de puntadas sobre un fondo de tela continua. Cada cuadro narra 
la historia de vida de una de ellas, es decir, el discurso de cada sujeto está asido al otro a través de las puntadas en zigzag que son un límite de la individualidad y la evidencia de un trabajo que construye sentido a partir de una acción grupal, con historias que se repiten. Si bien las representaciones visuales resultan ingenuas y recargadas, el relato verbal que las acompaña da cuenta de un trasfondo mucho más complejo y cargado de un realismo crudo que recién termina de dimensionarse en el relato oral de Fanny (la única del grupo de Nueva Zelanda que estuvo en presencia durante la exposición). A continuación se transcriben (textual) los enunciados que las refugiadas colombianas redactaron para acompañar a la pieza y que fueron puestos en sala:

\section{Rosa}

Cosiendo sueños: A partir del desarraigo que viví en Colombia... en el 2013 llegue al Ecuador llevando conmigo el sueño de poder vivir en un lugar estable. En Marzo del 2014 llegue a NZ. En esta tela queda plasmado un pasado, un presente y un futuro. Utilize el material harakeke (cultura maori).

\section{Marta}

Esperanza: Es la salida de mi país por fuerza mayor. La tela expresa mi odisea por tres países que abrieron sus puertas para poder refugiarme. Para plasmar mis experiencias de viaje. Mi intención es a través de mi inmigración abrir puertas para mis seres queridos.

\section{Maribel:}

Mi tela representa la persona que soy. Una persona humilde que a pesar de todos los obstáculos que he vivido, siempre he echado para adelante. Mi mayor motor es mi madre y mis hijos. Me encanta el campo, estar siempre con mis hijos, con plata o sin plata, yo siempre alegre con mis hijos y mis amigos de verdad me voy al parque o a la playa.

\section{Fanny:}

Mis raíces: Cuando era una niña mi madre cosía mi ropa. Mientras ella lo hacía yo la observaba y aprendí de ella. También cuando tuve 12 años mi madre me regaló dos máquinas y desde ese momento yo admiré las telas y las manualidades y lo que tenga que ver con usar mi imaginación y pensar.

Cuando tuve que dejar mi país fue muy difícil pero con ello me trajo agarrar lo que aprendí cuando era una niña y lo utilicé para sacar adelante a mi familia. Ahora que vivo en NZ me han ocurrido muchas cosas, unas muy lindas y unas muy tristes. Ahora mi nieta me ha hecho muy feliz...

Escuchar a las otras participantes las historias de pérdida y dolor me sirvieron para darme cuenta que se puede salir adelante, crecer y fortalecerse como mujer, madre, hija, abuela... me ha dado fuerza para contar mi verdadera historia. En el taller teníamos que dibujar nuestra historia, y no quería contar una historia triste y fea.

\section{Doris}

Traspasando fronteras: En este trabajo quise dar a conocer mis cambios de vida e interactuar con diferentes culturas y tradiciones, el valor que le damos a la vida y a nuestro planeta. 


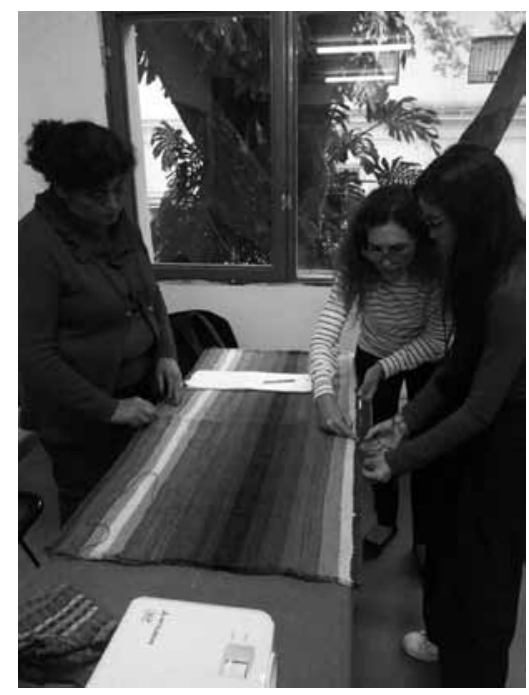

Foto 1. Imágenes del proceso y los resultados del trabajo grupal en el taller del MAP.

Benveniste nos dice que el lenguaje lleva en sí la posibilidad de la subjetividad, así como el discurso provoca la emergencia de esa subjetividad. Para estas mujeres esta manifestación discursiva plasmada en su collage textil constituye un hecho trascendente, ya que como refugiadas, y siendo que muchas de ellas han tenido que asumir nuevas identidades, debieron ocultar su verdadera forma de pensar y de manifestarse.

El autor de "De la subjetividad en el lenguaje", sostendrá que "es en y por el lenguaje como el hombre se constituye como sujeto" (Benveniste, 1966). A su vez Kerbrat afirma también que la lingüística de la enunciación estudia las huellas de subjetividad del emisor en su enunciado (Kerbrat, 1997).

Es el yo - aquí - ahora del discurso de estas mujeres lo que las constituye como sujetos, posicionados en nuevas identidades que afloran a través de la empatía -de acuerdo a la mirada de Martínez Azaro- hacia las demás miembros del grupo, con un mismo enunciado, pero dando cuenta de su propia diégesis a través de la enunciación, con los diversos elementos materiales y visuales que tuvieron al alcance para la realización de su obra.

\section{Caso \#2: El pájaro}

Textuales:

"Vine en el tren con mi telar, mi herencia, mis anhelos".

"Siempre sueño que tejo cuando sueño tejo que sueño".

"Con mis manos hilando recuerdos, sentimientos, ilusiones". 


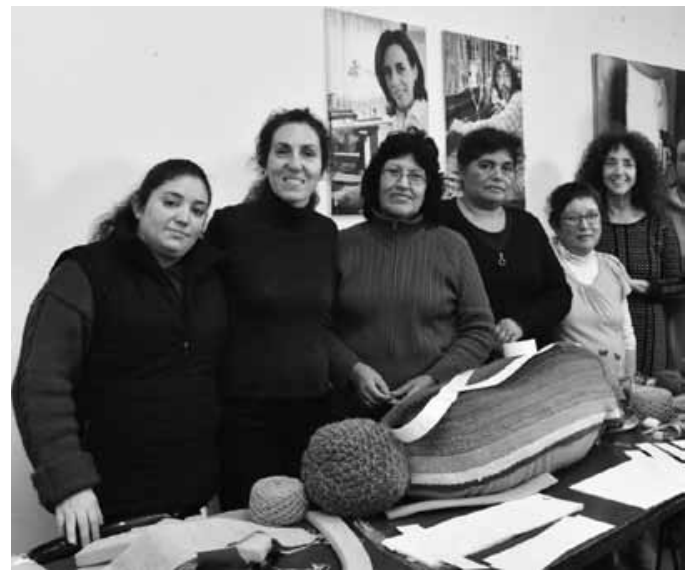

Foto 2. Taller Pertenencias en el MAP. Lourdes Huck, Ximena Eliçabe, Rosa Alancay Violeta Aybar, Amalia Barrionuevo y Felicitas Luna. Buenos Aires, 2019.

El pájaro es un objeto volumétrico, de aproximadamente $70 \times 40 \times 25 \mathrm{~cm}$. íntegramente tejido y bordado. Las técnicas tradicionales utilizadas en la realización del objeto "pájaro" dan cuenta de las regiones de donde proviene cada artesana. Su realización fue fruto del trabajo conjunto en el taller del MAP. Las frases transcriptas en el inicio de este caso pertenecen al resultado un ejercicio grupal donde cada artesana narraba algo que la relacionaba con su lugar de origen, con su relación con el hilado y el tejido. Escribíamos y recortábamos palabras de las que habían dicho en sus relatos, para compaginar la frase que luego sería bordada en la superficie tejida del objeto.

"Sin intención semiótica se construía un sintagma, es decir, la oración como unidad sintagmática del discurso. Considerando sintagma como unidad mínima con autonomía narrativa en que los enunciados interactúan semánticamente" (Metz, 1991).

En este caso documentado, los canales incluían el lenguaje verbal (oral y escrito), el sonido de las voces repitiendo las frases, lo visual y la imagen dinámica en movimiento del movimiento de las manos y las agujas que junto con la poesía sonora y textil, sensorial, táctil se registraba en video.

La metáfora del pájaro era capaz de reunir elementos de contextos muy diversos, traídos a la memoria por la repetición incansable del hacer, por el fugaz recuerdo de un lugar o un ser querido. Buscando las palabras, construyendo un discurso propio e irrepetible, las mujeres migrantes hicieron su alocución frente a la cámara, ante algunas preguntas generales ellas podían construir su enunciación entre el yo - aquí - ahora. Apropiándose de la lengua, en el acto de decir se construyen a sí mismas y al otro, en un mismo momento, el YO siempre se dirige a un TÚ. El Yo como punto de partida y el TU como el de llegada, el destino de su migración, el receptor.

A la vez 
El YO se establece como centro de referencia espacial, personal y temporal, que organiza el discurso... El enunciado remite a una acción originada en el lugar donde se posiciona el locutor, a una situación comunicativa donde se dice algo con cierta perspectiva, cosmovisión, ideología, para cierta inteligibilidad con el fin de causar un efecto... (Benveniste, 1966).

El discurso provoca la emergencia de la subjetividad.

Las condiciones de empleo de las formas - lingüísticas - no son idénticas a las condiciones de empleo de la lengua. Son en realidad mundos diferentes y puede ser útil insistir en esta diferencia que implica otra manera de ver las mismas cosas, otra manera de describirlas e interpretarlas (Benveniste, 1966).

\section{Caso \#3: la vicuña}

Descripción: media manta o rebozo de fibra de vicuña esquilada en el chaku (tradicional rodeo anual que se hace en semicautividad) en Laguna Blanca, pequeña población cordillerana de Catamarca, hilado a mano, tejido y bordado en los colores naturales de la vicuña con la figura de una mano que al abrirse deja salir pájaros que se van volando. Pesa apenas unos 200 gramos y mide $160 \times 50 \mathrm{~cm}$.

Transcripción:

He querido significar algo muy caro a nuestros sentimientos, como es lo de los tejidos y saber lo que se nos ha ido por cuestiones de búsqueda de mejor porvenir. Han quedado aquí familias íntegras un poco desorganizadas, hasta que se terminaron por ir todos los del grupo familiar, hasta los padres después. Lo que significa todo eso para mí tiene una carga emocional porque he querido representar a la madre Tierra, la mamá, la madre de la casa, la telera, tiene que despachar a sus hijos así. Por eso es que la manito es la que abre y de ahí larga a sus hijitos que son los pajaritos. Mucho significado de desarraigo y nostalgia he querido manifestar en este simple bordado (Juana Moreno de Herrero (dixit), Belén, Catamarca 12 de junio 2019).

Foucault en "Arqueología del saber", nos dirá, que importa el enunciado en sí mismo, este adquiere un papel central en su teoría, al cual considera no ya una mera 'huella' sino una materialidad con un determinado estatuto en el tiempo 'hoy'. Define al enunciado como elemento último, que no se puede descomponer, que puede ser aislado y entrar en juego de relaciones con otros, algo así como 'el átomo', dice, la mínima unidad del discurso. Para Foucault el enunciado es social, la enunciación es individual. 


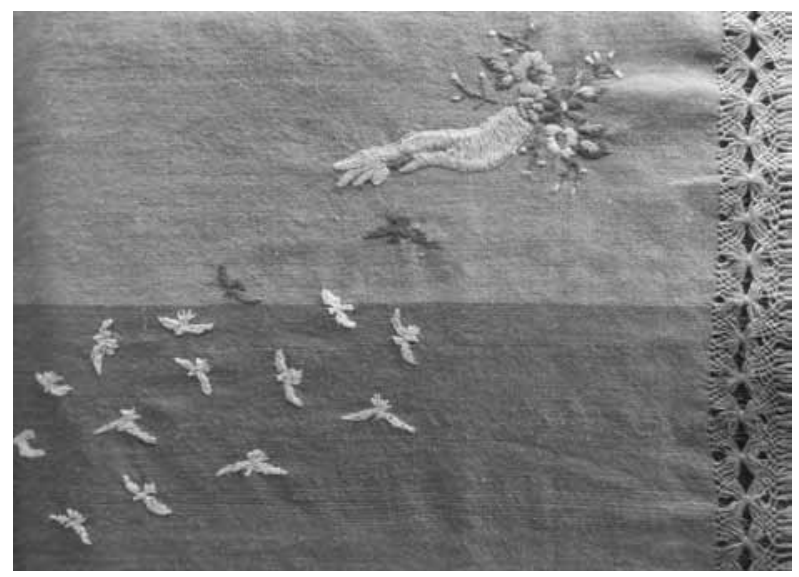

Foto 3. Manta de vicuña hilada, tejida y bordada a mano. Juana Moreno de Herrero, Belén, Catamarca. 2019.

\section{Respecto a la lectura de la materialidad}

En el caso de la pieza de Juana, la materialidad adquiere un carácter de signo. La vicuña es uno de los materiales textiles más preciados, incluso más que la seda o el cahsmir; ya desde épocas preincaicas era considerado atributo de los dioses y reservado para ser utilizado por las castas dominantes. La relación entre lo suntuario y lo sagrado es un signo muy marcado en la cosmovisión de los pueblos precolombinos. Tiene que ver con lo escaso, lo frágil, lo sublime.

Joanne Pilsbury, curadora de la muestra Reinos de Oro. Arte suntuario en la América Precolombina, realizada en el MET de New York en febrero de 2018 sostiene en su texto curatorial:

Los materiales utilizados en el arte suntuario de la América precolombina se encontraban estrechamente asociados al poder divino: según se creía, eran materiales que habían sido emitidos, habitados o consumidos por los dioses. Las obras de arte suntuario eran también relativamente pequeñas, lo que significa que podían transportarse por largas distancias y entregarse como obsequios reales y ofrendas sagradas, para servir así como vehículo principal del intercambio de ideas entre regiones y entre épocas (Pilsbury, 2018).

El alto grado de significación de su materialidad se expresa por lo anteriormente mencionado, y por el tiempo de dedicación y trabajo que lleva el procesamiento de la fibra, de un muy bajo rendimiento en volumen. Ese trabajo es sólo ejecutado por manos hábiles y entrenadas tras muchos años de oficio.

$\mathrm{Al}$ igual que en los casos anteriores, la representación figurativa del bordado parece aludir a un tema romántico o incluso ingenuo, sin embargo está cargado de significación. La 
misma comienza a leerse a partir del material para terminar en la escena representada, pero sólo se completa con la enunciación de su autora, que con su tono tranquilo y su acento provinciano, de manera intuitiva pero asertiva va al núcleo del marco teórico de la muestra.

Así como en el caso de la artesana que desde su contexto natural, es capaz de ver a la distancia y de enunciar una problemática que atañe tanto a los que se quedan como a los que se van. Desde su lugar de origen, estando en una posición privilegiada respecto a las demás artesanas mencionadas en los casos anteriores, es ella quien está en contacto con el material sagrado que le provee su tierra.

En el grupo de las artesanas migrantes en Buenos Aires, se aferran a la materialidad que les exige su técnica, lo que les da la seguridad de saber hacer, mandan a traer materiales de sus lugares de origen, fibra de llama y lana de Catamarca, hilo de algodón del Paraguay para el Nandutí.

No obstante el grupo de Hamilton es el que tuvo que dejar atrás más cosas, reinventarse, y no es casual que su materia prima sean los descartes de la moda de alta gama del mundo desarrollado, y algunos pequeños elementos a los que pueden acceder, como granos de café, plumas y recortes de telas estampadas con motivos folklóricos.

\section{Transparencia u opacidad}

A raíz de estas consideraciones retomaremos las postulaciones de Recanati respecto al signo y el carácter opaco o transparente de la enunciación.

Es la noción de signo la que es intrínsecamente paradójica, pero este género de paradoja no debe evitarse a toda costa; es preciso más bien, tratar de servirse de ella para aprehender la especificidad... Lo que está en juego es importante, pues la noción de signo, por más paradójica que parezca a primera vista, es necesaria para aprehender válidamente, por ejemplo, la estructura de nuestros pensamientos (Recanati, 1981).

En los casos abordados nos encontramos con signos -en especial desde el lenguaje visualque en una primera lectura velan el verdadero significado del pensamiento de sus autoras. Sin embargo el significado se hace palpable con la enunciación, a partir de la incorporación el lenguaje verbal, tanto escrito como oral, en cruce con el lenguaje visual (de las telas como en los testimonios en video) nos revela el verdadero objeto de su representación. Por su carácter doble, el signo es opaco y transparente a la vez. "Descubre y oculta la cosa significada, se refleja al mismo tiempo que representa algo distinto de si” (Recanati, 1981). En un enunciado distinguimos lo que se dice y el hecho de decirlo, tal como distinguimos en un pensamiento, lo que se piensa y el hecho de pensarlo.

El sentido de un enunciado no puede considerarse independiente del hecho de su enunciación. 

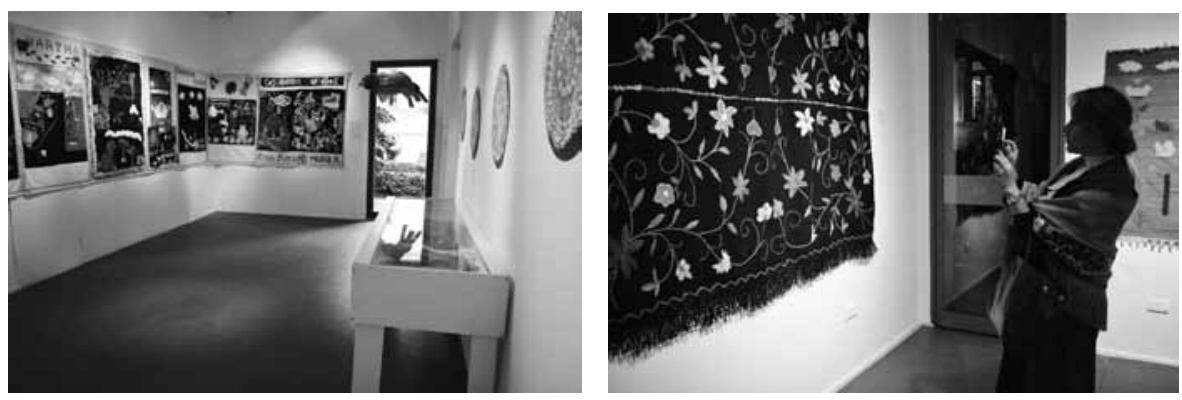

Fotos 4 y 5. Sala de exposición Pertenencias en el MAP.

El pensamiento es como la idea, un signo, pues es una cosa que representa otra cosa. ...La idea es signo de aquello de lo que es idea: la idea es signo de su objeto, la idea de rosa es signo de la rosa. La cosa significada (la rosa) existe independientemente de la idea de la que es objeto, o no existe más que como idea del objeto?... aunque el objeto no exista independientemente de la idea, la idea representa el objeto como algo distinto de si (Recanati, 1981).

Y agrego un párrafo de la poesía de uno de nuestros grandes, que parece haber predicho todas estas postulaciones:

Si (como afirma el griego en el Cratilo)

el nombre es arquetipo de la cosa

en las letras de 'rosa' está la rosa

y todo el Nilo en la palabra 'Nilo'.

(Borges, J. L. El Golem, 1964)

\section{Más preguntas que respuestas}

¿En conclusión, pienso, en dónde está la frontera entre el pensamiento, la idea y el objeto representado?

¿Cómo migra ese acto mental y es transformado en signo con respecto al contenido que vehiculiza?

¿Cómo actúa la opacidad del signo como un primer escudo que resguarda la ferocidad de la realidad que está detrás del pensamiento?

¿Es la enunciación un mecanismo que atribuye transparencia en un discurso complejo y multidimensional? 
¿Está el enunciado, como mínima unidad del discurso, compuesto por una materialidad que no puede descomponerse ni ser aislado? ¿Está afirmado en lo social y en el tiempo hoy como postulaba Foucault?

Tal vez esta frase resuma alguna de las respuestas a mis preguntas:

"No se trata de buscar los orígenes perdidos o borrados, sino de tomar las cosas allí donde nacen, en el medio, hender las cosas, hender las palabras..." (Deleuze, 1996).

\section{El viaje mítico-simbólico}

El viaje migratorio de estas mujeres encarna de alguna manera la idea del viaje mítico, ya que ellas para poder reinventarse tuvieron que perder otras cosas en el camino. Sin embargo aquello que mantiene viva la llama de su identidad, que las conecta con su origen, es el lazo materno -dado que la transmisión de saberes se produce de madres a hijas o de abuelas a nietas- a través de su contacto con el textil como vehículo. Cada una es un ejemplo de vida, se sobrepusieron a circunstancias muy difíciles pero salieron adelante. Aportaron su conocimiento y experiencia al grupo, con lo cual todas aprendimos. Cada una viene con su propio bagaje, con sus Pertenencias. Nuestra tarea fue sólo encontrar la punta del ovillo, proponer un acercamiento a los temas que se desprenden de estas historias de vida, con sus discursos, su relación con el poder, con sus luces y sus sombras, en el aquí y ahora, también allá donde todo comenzó y estas historias continúan ocurriendo.

\section{Notas}

1. https://www.youtube.com/watch?v=t8dVgxEZHqU

\section{Bibliografía}

Benveniste, É. (1995). Problemas de Lingüística General II. México: Siglo XXI.

Deleuze, G. (1986). Foucault. Barcelona/Buenos Aires/México, 1987: Paidós.

Escobar, T. (2009). El arte fuera de si. IVAM Documentos Iberoamericanos. Institut Valenciá d'Art Modern. Valencia, España.

Foucault, M. (1996). La arqueología del saber. 17a edición , México: Siglo XXI. (1ª. Edición 1969).

Heredia, P. E. (1996). Exilio y región. Los discursos de la resistencia cultural (Un estudio de la narrativa argentina de los 70 y 80). Jorge Torres Roggero (comp.), Calíbar sin rastros. Córdoba: Universidad Nacional de Córdoba, pp. 189-212. Consultado on line en http:// www.cervantesvirtual.com/obra-visor/exilio-y-region-los-discursos-de-la-resistenciacultural-un-estudio-de-la-narrativa-argentina-de-los-70-y-80/html/9... 
Kerbrat Orecchioni, C. (1997). La enunciación de la subjetividad en el lenguaje. Buenos Aires: Edicial.

Recanati, F. (1981). La transparencia y la enunciación. Introducción a la pragmatic. Buenos Aires: Hachette.

\author{
Anexo \\ Imágenes y videos disponibles en: \\ GoogleDrive: https://drive.google.com/drive/folders/1OuIZvfqn_f9aV935PasPmT1HXTe \\ YCoRY?usp=sharing \\ En Youtube: https://www.youtube.com/watch?v=t8dVgxEZHqU
}

\begin{abstract}
This paper is a study of the production of meaning generated from the textile work of different craftswomen who participated in the project Belongings, textile stories of migrant women in the Southern Hemisphere.

Taking into account the systems of representation in the production of images as relations that are established between the discourse, the subject and the historical-social processes, it aims to find in the discursive dimension of the work, as well as in the verbal discourse of its authors, those elements that build two apparently opposite stories. The naive image of the textile collage and embroidery, as opposed to the harsh reality that they have lived to those who made it, narrated by them in interviews on and off the record.
\end{abstract}

Keywords: migration- textile art - discourse - materiality - enunciation.

Resumo: $\mathrm{O}$ artigo resulta de um estudo da produção de sentido gerada a partir do trabalho têxtil de diferentes artesãs que participaram do projeto "Pertencimento, narrações têxteis de mulheres migrantes no Hemisfério Sul”.

Considerando os sistemas de representação na produção de imagens como sendo relações estabelecidas entre o discurso, o sujeito e os processos histórico-sociais, almeja encontrar na dimensão discursiva da obra, tanto como no discurso das suas autoras, aqueles elementos que constituem dois relatos, em aparência, opostos. A imagem ingénua da colagem têxtil e do bordado, é contraposta à dura realidade que os realizadores precisam viver, narrada por eles mesmos em entrevistas on e off the record.

Palavras chave: migração - arte textil - discurso - materialidade - enunciação.

[Las traducciones de los abstracts fueron supervisadas por el autor de cada artículo] 